\title{
28 Research Suare \\ Card Sorting: A new pedagogy for understanding challenges in Mathematics during Emergencies and Crises
}

\author{
Sione Paea ( $\nabla$ sione.paea@usp.ac.fj) \\ The University of the South Pacific \\ Bibhya Sharma \\ The University of the South Pacific \\ Gabiriele Bulivou \\ The University of the South Pacific \\ Mele Katea Paea \\ The University of the South Pacific
}

\section{Research Article}

Keywords: Card sorting, Challenges, Similarity matrix, 3D Cluster View (3DCV), Higher Education Institutions, Mathematics

Posted Date: May 4th, 2021

DOI: https://doi.org/10.21203/rs.3.rs-351612/v2

License: (c) (i) This work is licensed under a Creative Commons Attribution 4.0 International License. Read Full License 


\section{Abstract}

Interest in challenges faced by university students during COVID-19 has led to research and development initiatives that include educational, technological, economical and socio-cultural provisions. Despite these initiatives, little is known about the usage of open card sorting, similarity matrix, and Hierarchical Clustering Method - 3D Cluster View algorithm in understanding and analysing mathematics challenges in a regional university during emergencies and crisis. This paper presents findings from a study that explored the challenges encountered by first-year mathematics students in a South Pacific institution. The findings reveal seven challenges: i) financial hardship; ii) motivational challenge; iii) moodle issues; iv) lack of face to face interactions; v) problem with course delivery; vi) internet challenge; and vi) home disturbances. A heptagon model is presented with possible solutions for the challenges identified by participants. The findings point to the complex inter-relationship between the institution's emergency remote teaching, students' learning needs,

and students' dynamic socio-cultural environments as important factors for delivering quality mathematics learning during a pandemic. This paper highlights the contribution of card sorting, as a new pedagogy, to the field of educational research as a provider of new learning analytics for desirable learning outcomes in a given pandemic. Decisionmakers and Policymakers of Higher Education Institutions around the world may benefit from these findings while formulating strategies to support first-year mathematics students during the current and future pandemics.

\section{Introduction}

The world is currently experiencing and gradually responding to a widespread of transmissible respiratory disease caused by an original coronavirus named COVID-19. The disease was declared a global pandemic by the World Health Organisation (WHO) on March 11, 2020. Over 1.5 billion students in 165 countries are affected by COVID-19 related school closures, equivalent to $87 \%$ of the world's student population. To protect this population from the spread of COVID-19 as a contagious and deadly virus, the emergency remote teaching (ERT) has been an overwhelming response of many Higher Education Institutions (HEI) around the world (Mulenga and Marbán 2020).

The global shift to ERT (Bozkurt and Sharma 2020; Hodges et al. 2020; Karakaya 2021; Trust and Whalen 2020; West et al. 2020) and its actual application using online platforms has posed many unexpected challenges that students, parents, and institutions were not adequately prepared for. This includes issues regarding technology, home learning environment, internet network capacity, and time conflicts between work and online learning sessions (Mohmmed et al. 2020). In most cases, students have complained about difficulties in gaining access to educational resources and completing activities and assessments. On the other hand, the universities are concerned with the lack of student engagement in an ERT learning environment (Affouneh 2020).

The challenges of supporting learner interests and understanding through online education are welldocumented, which include feeling of disconnection (Choudhury and Pattnaik 2020), difficulty to meet individual learning needs (Haavind and Sistek-Chandler 2015) and lack of self-direction (Beaven et al. 2014). These challenges were exacerbated during the pandemic, where many educators and learners suddenly immersed in unfamiliar and unaffordable situations (Blum-Smith et al. 2020). Studies on understanding 
university teachers' design work emphasise the significance of looking into what teachers actually do in the process of instructional designing and planning activities (Bennet et al., 2017) because learning design during an ERT can be dynamically shaped (Karakaya, K., 2020). The fact that learning mathematics in the online environment has always been an issue, sudden shifts to online in emergencies without due process will make learning even more difficult and unsustainable. This underscores the significance of the current study and the crucial role of the university in transforming teaching-learning practices towards a sustainable learning environment.

Research explores the challenges faced by first-year mathematics students during the unexpected shift to ERT due to COVID-19 lockdown restrictions in a regional university. The objective is to have a better understanding of those challenges and to propose a new learning support model that can strengthen quality learning in mathematics in an emergency. Such a model can guide the institution to cultivate stronger learning strategies of resilience during a pandemic and to ensure better preparation for the next inevitable emergency and crisis. The term challenge is defined in this paper as the difficulties, problems or issues that affect students' learning ability to achieve during the sudden change of learning modes in an emergency response.

An open card sorting (OCS) (Paea et al. 2020) was employed to explore the topic by drawing cards initially from the institution's understanding of students' experiences whilst studying mathematics during the COVID19 lockdown. A total of seven challenges were commonly shared amongst participants' findings: i) financial hardship; ii) motivational challenge; iii) moodle issue; iv) lack of face-to-face (f2f) interaction; v) problem with course delivery; vi) internet challenge; and vii) home disturbance. These challenges are made up of different inter-related components that should be understood and addressed from a dynamic multi-dimensional perspective. It highlights the complex way of life that Pacific students live their lives in a given context, which cannot be separated from their learning experience during emergencies and crises. This provides direction to the university about the need for a long-term emergency system in place that would involve clear investment and coordination for the future.

The main contributions of this paper are as follows:

1. the important role of card sorting in the field of educational research as a provider of new learning analytics for quality learning in mathematics and desirable learning outcomes from a range of known and unknown inputs in a given pandemic; Card sorting has classified and analysed the findings in a more organised manner;

2. the appropriate use of fit values of stress and R-squared to choose the best fit model data. New insights suggest the three-dimensional solution an appropriate model for card sorting datasets;

3. the use of card sorting and resulting analytics points to a significant association between emergency remote learning in mathematics, socio-cultural student challenges, and quality learning in a given pandemic. The implication is that the $3 \mathrm{DCV}$ process was effective in determining relationships among challenges (items) in a manner that is more effective than applying a general logic approach;

4. new direction beyond student perceptions and outcome measures. The heptagon model can replicate with a broader coverage of the major conditions that contribute to online instruction quality at times of 
emergencies and crises;

5. use of new heptagon model for better comprehending of the complex nature of mathematics students' learning experiences in a South Pacific regional university, calling for a more inclusive, affordable and sustainable ERT. The findings can be applied in any learning environment with special attention given to learners' dynamic socio-cultural backgrounds that should include contextualisation.

The paper consists of 8 sections, including this introductory section. The next two sections provide a brief description of the research context and the literature relevant to the research topic. This is followed by research strategies in section four then the questionnaire in section five. Later in section six is the presentation and discussion of findings followed by demonstrating potential solutions for participants' challenges in a heptagon model in section seven. The final section concludes the paper.

\section{Research Context}

The USP is one of only two regional universities in the world. It is jointly owned by the governments of 12 member countries across the South Pacific region: Cook Islands, Fiji, Kiribati, Marshall Islands, Nauru, Niue, Samoa, Solomon Islands, Tokelau, Tonga, Tuvalu, and Vanuatu. The role of the USP in developing the knowledge economy of the region places the university in a unique position in relation to education and research. The university has campuses in all member countries, and the current study was fully implemented at the main campus, Laucala, in Fiji. After the announcement of the first case of COVID-19 in Fiji on March 19, the USP was totally closed down for 2 weeks, March 26 - April 9, before the University began its emergency remote classes in the second half of the first semester for 7 weeks from April to June 2020. The courses returned to normal blended mode ( $f 2 f$ and online) at the beginning of the second semester of 2020.

During the 7 weeks of ERT at the USP, the authors found student's self-discipline at the core of their own success. Mathematics students with high self-discipline could follow instructions and complete work on time, whereas those with low self-discipline would be impossible. When students' learning behaviours cannot be monitored remotely, their lack of self-discipline would greatly impact their learning outcomes. The unexpected shift to ERT also required teaching staff to use new software and unfamiliar online tools without having proper technical support. A significant challenge for HEl teachers has been their lack of the pedagogical content knowledge (PCK) (Tondeur et al. 2020; Shulman 1987) needed for teaching online (Kali, Goodyear and Markauskaite 2011; Ching et al. 2018). Accordingly, the use of digital and technological resources for ERT of mathematics has increased sharply. Still, its success can only be guaranteed when the teachers are competent and ready to develop and utilise these resources. This reinforces the need for HEI to be more prepared for the future, emphasising the important contribution the current study can offer to achieve that from a Pacific learning perspective during an emergency.

\section{Literature Review}

Some recent studies on ERT highlight different types of challenges experienced by students during the unexpected educational shift (e.g., (Aguliera and Nightingale-Lee 2020; Bozkurt and Sharma 2020; Hodges et 
al. 2020; Mohmmed et al. 2020; Mulenga \& Marbán 2020). A study that explored students' lived experiences as impacted by emergency shift to remote teaching in the United States of America confirmed that students with existing educational inequality had been exposed to more learning inequalities during the abrupt shift to ERT (Aguliera and Nightingale-Lee 2020; Trust and Whalen 2020). Students had to provide their own learning resources that put them at a great disadvantage in relation to the unsafe learning environment, poor access to the internet and inability to possess electronic devices (Aguliera and Nightingale-Lee 2020; Zilka et al. 2018). Those students who do not have access to laptops or high-speed internet at home would experience more severe learning challenges, which may delay the acceptance of technology-enabled education (Zilka et al. 2018). These resources (non-financial such as computer, internet access) are crucial to obtain HEl goals and become essential home possessions during emergencies and crises

The ERT also comprises of issues including time management, technology illiteracy, students' assessment, communication, and the lack of in-person interaction (e.g., (Karakaya 2021; Steele 2019). Interacting online requires educators to rethink online pedagogy so as to support meaningful (higher-order) learning and its assessment (Gikandi et al. 2011; Ćukušić et al. 2014). Aside from online infrastructure challenges, Bozkurt and Sharma (2020) argue for more attention to the lack of empathetic support for students during the crisis of COVID-19 because "students will remember not the educational content delivered, but how they felt during these hard times" (Bozkurt and Sharma 2020). This presents the importance of motivation and self-esteem protection, during an ERT, for resilience and quality learning.

Mulenga and Marbán (2020) explore the perspectives of teachers who were engaged in teaching mathematics online during COVID-19 and found that educators, teachers, and ERT staff need better training and support for using online tools (Trust and Whalen 2020). These challenges give direction to the future, calling for the institution to work in collaboration with stakeholders to offer better solutions in preparation for future interruptions (Bozkurt and Sharma 2020) and to formulate more forward-looking strategies towards improving teaching-learning activities during COVID-19 ERT (Mohmmed et al. 2020). With the rise in the use of online modalities during COVID-19, it is necessary to assess their effectiveness regarding teaching and learning from different stakeholders (Schwartz et al. 2020). The nature of online learning means that working in partnership with numerous digital innovators and instructors who see technology as a method of solving problems and reaching new learners is needed.

The use of card sorting to explore mathematics students' challenges during a pandemic in the South Pacific has been absent. However, the practical guidance on card sorting in a Pacific HEl will help to understand how it can be implemented appropriately in the Pacific context (Paea et al. 2020). Card Sorting is utilised to evaluate the information architecture (IA) of a finding and to design a navigation structure that can offer an exciting variety of content and functionality (Righi et al. 2013). The IA of the current research refers to the challenges that emerged from this study in relation to first-year mathematics students' learning experiences during the emergency and crisis of COVID-19. It provides insight into users' mental models (Katsanos et al., 2019), revealing how they often implicitly group, sort, and label tasks and content within their own heads according to their understanding. The term card sort applies to a wide range of activities, including ordering, grouping, and/or naming objects or concepts (Paea and Baird 2018). With card sorting, researchers learn how users categorise and label their thoughts to express their feeling and experience in a challenging 
situation. Card sorting provides a map of users' knowledge of the content and where they might look for the content within the design of an actual interface display.

Card sorting also has applications in visualisation research. For example, it has been used to explore people's mental models of classifying visualisation methods. It has also been used as a way to conduct a task analysis of geovisualisation tools and interactions (Lloyd et al. 2007). Using the card sorting method in this study aims to target the users' understanding of the challenges based on their experiences during the shift from $\mathrm{f} 2 \mathrm{f}$ to ERT. This is also the first time to utilise the card sorting method to generate useful insights about the research question. Efforts to develop, understand, and productively use card sorting data have organised into a field of educational research.

The need for a better understanding of first-year mathematics students' challenges during COVID-19 using card sorting approach in a Pacific learning context is highlighted by its absence in the literature. It appears from the ERT literature that students' challenges during the emergency and crisis of a pandemic is complex in a way it is based on the dynamic inter-relationships between students' home learning environments, students-teachers digital literacy, course delivery, internet network access, students' motivation, and the sociocultural contexts in which students live and operate. These challenges set the foundation for exploring the research topic, which offers timely insights to the gap in the literature of interconnectivity between card sorting, quality learning in mathematics, ERT, and Pacific regional HEI.

\section{Research Strategies}

\subsection{Population, setting, and sample}

The target population is the first-year or 100 level students who studied mathematics at the USP in semester one (February - June) of 2020. Targeting first year $\mathrm{f} 2 \mathrm{f}$ mathematics students is essential for understanding their learning needs as new entrants to the university during a pandemic and how best to support them towards persistence or successful completion of mathematics courses. This also provides a more realistic insight into the challenges that mathematics students faced while going through unprecedented change to teaching and learning during the university's COVID-19 lockdown.

Since it was impractical to explore the topic with the complete USP population across the university's regional campuses, the research team chose the Laucala campus in Suva, Fiji, because this setting recruits the highest proportion of first-year face-to-face mathematics students. It is also the most central setting considering COVID-19 restrictions on regional travels in the South Pacific. The respondents in the target populations were recruited by convenience sampling facilitated by advertising on MA111 moodle page. The study recruited a total of 32 ( 16 men and 16 women) first-year mathematics students who are currently studying at the USP and citizens of the university's country members. Such a recruitment reflects the diverse realities shaping the formation of learning at the USP, and the complexities involved with direct and indirect impacts of pandemic on students' learning experiences. The participants' ages ranged from 18 to $28(M=20$ and $S D=2.9$ ). 
The authors' decision to recruit 32 participants is based on their experience as card sorting researchers and from reviewing of previous card sorting studies that have examined the adequate sample size needed to produce high-quality representation (Optimal Workshop; Tullis and Wood 2004; Wood and Wood 2008). Tullis and Wood (2004) found that a sample size of 20-30 participants explains $90-95 \%$ of the true information space structure, with diminishing returns in explanatory power as the sample size increases beyond 30 . Wood and Wood (2008) confirmed that recruiting as few as 25-30 participants would likely yield results similar to those of several hundred provided these participants are representative of actual users and are familiar with the domain being considered.

Rosas and Kane (2012) indicated the variability in each study's stress values was dramatic when about 15 or fewer participants were included. As the number of participants for each of their five studies reached about 35 participants, substantial improvements in stress (i.e. lower stress values) were observed. However, beyond 40 participants, only marginal improvements in stress were detected. These findings suggest between 20 and 30 participants is warranted to maximise the consistency of fit in the concept mapping representation by minimising the variability in the stress value found with smaller groups of participants. For open card sorting, the ideal sample size is between 30 and 50 participants as supported by Card sorting 101 (Optimal Workishop). Completed card sorts within this sample interval would be easy to identify ideas and consensus (Optimal Workshop). Also, keep in mind that the more participants you have completed your card sort, the potential for more complexity in your analysis increases as well. This is simply because narrowing down the most effective structure from 40 different suggested categorisations will probably be easier than 200 various suggestions. Also, Research suggests a minimum of 15 users to obtain robust data from open card sorts (Katsanos 2018; Nielson 2004; Tullis and Wood 2005), thus our studies had adequate sample size. Hence the authors decided to recruit 32 participants as the sample size.

Participants were recruited through a variety of means including personal contacts, referrals and voluntary. The authors then administered the research announcement to the students who were enrolled in MA111. The Moodle message, course announcement via Moodle and email distribution were used to inform the students about the research and encourage them to participate voluntarily. Participants were also recruited using an informal snowball process that was based on researchers' cultural knowledge and skills of recruiting Pacific participants through networking and relationship building (Paea et al. 2020). This type of recruitment is important for building trust and respect amongst participants and the researcher because Pacific people can willingly partake when they trust the researcher; and know their contribution is recognised and valued (Paea et al. 2020).

Prior to the day of the actual card sorting, a card sorting demonstration video and an information sheet were sent to participants beforehand. This is to provide participants with relevant information about the research objectives, how to do card sorting, and how it would affect them during and after the fieldwork.

\subsection{Card size and names}

A total of 44 physical card names were drawn from the university's in-house report on the challenges facing first-year mathematics students in the process of a sudden shift to emergency remote learning. The 44 cards 
are related to each other in the sense of challenges, but they clearly comprehend the group's own cluster by the participants. This was supported by two mathematics lecturers' experience in the current research team to generate a Pacific solution-based framework to strengthen students' resilience and retention during a pandemic. Card names represent the challenges, problems, or issues that hinder students' ability to achieve during the unforeseen shift. The names were made in a lower-level meaning for participants to understand. For instance, the card name 'internet data is expensive' means that students cannot access to online learning because of financial hardship and the card names are related to each other. The physical cards are chosen to align with what most studied recommended (Optimal Workshop; Tullis and Wood 2004).

\subsection{Face-to-face open card sorting}

The study was implemented through open card sorting (OCS) in $\mathrm{f} 2 \mathrm{f}$ mode because the nature of sharing responsibilities and co-constructing meaning between participants and the researchers have strengthened the quality of their relationship and the findings (Paea et al. 2020).

On the day of $\mathrm{f} 2 \mathrm{f}$ card sorting, one of the researchers welcomed participants by acknowledging their presence, time, and contribution. Participants were allowed to introduce themselves including their Pacific originalities because it gave them a sense of belonging to the card sorting context. The researcher went on to brief participants about the research objectives, informed them that their personal details would be kept confidential, and allowed them to ask questions about the research before they signed the consent form.

A pile of 44 physical cards was placed on the table. Participants were asked to sort the cards into groups of similarities and labelled groups according to the challenges they experienced during the unexpected change from $f 2 f$ to ERL. The participants performed the card sort individually to assure independence of grouping strategies. For each participant, the authors took a photo of the final card sorting and audio-recorded their verbalised thoughts. Additionally, audio recordings were transcribed and analysed to provide valuable insight, detailed data pre-processing and elaborate them to rich visualisation. The participants' details were kept anonymous and the responses were only used for analysis purpose.

The actual time of card sorting varied from 30-70 minutes to complete. Some participants created just four categories, while others created more complex classifications involving up to 10 categories $(M=7, S D=1.5)$. There were no significant differences between the number of categories formed by males $(M=7)$ and females $(M=7), t(7)=0.88, n s$, and the number of categories formed was unrelated to age $(r=-0.23, n s)$. Once participants had grouped the challenges, they named each grouping they had formed to help explain commonalities between the challenges contained within the grouping.

Figure 1 illustrates participants' pathway through the f2f OCS during an active card sorting performed by one of the participants. It shows how $\mathrm{f} 2 \mathrm{f}$ card sorting is conducted using physical cards in an OCS. During the actual performance, participants were allowed to move cards to ensure their experiences were consolidated. The blue sticky papers on top of each column represent the group numbers with unknown category names, and sorted cards are presented under each blue coloured paper. The category names were numbered for ease of reference. 


\subsection{Card sorting analysis}

There were two main phases to the analysis. The first phase was the construction of similarity matrices to test how strongly the group elements of challenges are related to each other. The second phase was a 3DCV analysis of the card-sort data (Optimal Workshop ; Paea \& Baird 2018; Paea et al. 2020). To ensure usability and simplicity for better comprehension of participants' challenges, the category labels were revised. For example, in Group 3 of Table 1 ( $p$ 14), there are 3 commonly shared categories based on participants' data: financial issues ( $82 \%)$, challenges with rolling expenses (80\%), and family financial background $(78 \%)$. Since all these categories represent participants' financial difficulties, the category name 'financial hardship' was used. While these steps can be seen as modifying the original data, it enhances data consistency and clarity without changing the meaning of participants' original data. This process of co-constructing meaning between participants and the researcher(s) is acceptable in the Pacific Way of carrying out card sorting research (Paea et al. 2020).

\subsubsection{Phase 1: Similarity Matrix}

A a similarity matrix was constructed to represent the raw card sort data. A matrix was created for every participant, indicating whether each pair of strategies was placed in the same grouping (" 1 ") or in a different grouping (" 0 ") in the participant's card-sort solution. These matrices were then aggregated cell-by-cell to create a matrix with cell values ranging between 0 (if no participants had placed a particular pair of challenges in the same group) and 32 (100\%) (if all participants had placed the pair in the same group).

The similarity matrix is used to interpret how strongly the group elements of challenges are related to each other. Since the research has considered card names as representation of participants' learning challenges during an emergency, the similarity matrix in Figure 2 is a straightforward representation of cards combinations. It intends to give insights into the challenges that participants pair together in clusters, which also identify pairs of closely related challenges by assigning them higher similarity than those that are distantly related. The similarity is measured between two individuals in the cards of challenges, with the similarity matrix being formed by combining this information for all pairs of challenges. For instance, the first column of the matrix shows that $87 \%$ of participants put the challenges 'expensive to buy relevant software' and 'cannot afford to buy the textbooks' in the same group; meaning that both cards are interconnected highlighting participants' financial difficulties as the lead cause of their learning challenges during the pandemic. Looking further down the same column, 'expensive to buy relevant software' and 'not working hard enough on assessment' were never placed together. This means that participants' financial and motivational challenges are not related.

Accordingly, the strongest pair is positioned at the top left corner, grouping them with the next associated strongest pair that either of those challenges have, and then the process is repeated for that new pair. This way, groups of challenges that are strongly related to each other appear together in the same shade of blue on the similarity matrix. The darker the blue shaded areas where two challenges intersect, the more often they were paired together by the participants (Optimal Workshop; Paea \& Baird, 2018; Paea et al., 2020). 
It can be seen from Figure 2 that the blue shaded areas have an inconsistent pattern. The authors subsequently display the data that are positioned along the right edge in Figure 2 as a line graph (Figure 3 ) to identify possible major challenges of clusters. The technique can assist in finding a suitable analytical method to analyse the finding. For instance, in Figure 3, the red colour can be potential clusters. The black colour is threatening to decide if these challenges belong to a particular cluster due to low participant agreement. With the inconsistent patterns and low participant agreement, the 3D Cluster View (3DCV) is utilised to visualise the data clearly in Figure 2 by grouping the challenges in 7 clusters, as demonstrated in Figure 5. The next section describes how the authors' finalised the total number of categories in 7 clusters.

\subsubsection{Phase 2: Number of Clusters}

One important challenge that arises in quantitative analysis of card sort data is deciding the optimal number of clusters. In the initial solution, the number of clusters is equal to the number of cards included in the study, that is 44 physical cards (see Table 1). This paper uses the approached by Katsanoe et al. 2008 based on the widely used eigenvalue-one criterion to identify the optimal number of clusters. Every cluster has an eigenvalue representing the amount of variance accounted for by a given cluster. Usually, the first variables have the greatest eigenvalues. The method identifies the optimal number of clusters in terms of variance explained by implementing an eigenvalue analysis of the challenges' similarity matrix (Figure 2) and keeping only the eigenvalues greater than 1 (see Table 1). Table 1 shows that only the first seven components have the eigenvalue greater than one.

Another method used for factor extraction is the analysis of the scree plot (Cattell 1966) or elbow criterion. According to this criterion, the significant factors are disposed like a cliff, having a big slope while the trivial factors are disposed at the base of the cliff. This is achieved by plotting the eigenvalue against the number of clusters (see Figure 4a). Also, plotting the percentage of variance explained against the number of clusters (see Figure $4 \mathrm{~b}$ ). In Figure $4 \mathrm{a}$ and $\mathrm{b}$ we can appreciate that starting with the seven-factor the slope of the curve is relatively small and these factors could be excluded from the model. Nevertheless, Figure 4 is very subjective because the curve's cut-off point is sometimes not very clear. Then we compare the result from Table 1 and figure 4 with the Optimal Workshop 3D Cluster View algorithm. This is calculated simply by taking the average (mean) of the number of categories created by participants in the survey. 3D Cluster View algorithm also provided seven clusters and the result agrees to the finding in Table 1 and Figure 4 . Then the author's concluded the optimal number of clusters is seven.

Table 1: Total variance explained. 


\begin{tabular}{|c|c|c|c|c|c|c|}
\hline \multirow{2}{*}{ Component/ Cluster } & \multicolumn{3}{|c|}{ Initial Elgenvalues } & \multicolumn{3}{|c|}{ Extraction Sums of Squa red Loadings } \\
\hline & Total & $\%$ of Varlance & Cumulative $\%$ & Total & $\%$ of Varlance & Cumula tive \% \\
\hline 1 & 16.138 & 36.678 & 36.678 & 16.138 & 36.678 & 36.678 \\
\hline 2 & 6.200 & 14.091 & 50.768 & 6.200 & 14.091 & 50.768 \\
\hline 3 & 2.669 & 6.065 & 56.834 & 2.669 & 6.065 & 56.834 \\
\hline 4 & 1.749 & 3.975 & 60.808 & 1.749 & 3.975 & 60.808 \\
\hline 5 & 1.325 & 3.012 & 63.820 & 1.325 & 3.012 & 63.820 \\
\hline 6 & 1.145 & 2.603 & 66.423 & 1.145 & 2.603 & 66.423 \\
\hline 7 & 1.061 & 2.412 & 68.834 & 1.061 & 2.412 & 68.834 \\
\hline 8 & 0.981 & 2.231 & 71.065 & & & \\
\hline 9 & 0.899 & 2.044 & 73.109 & & & \\
\hline 10 & 0.845 & 1.920 & 75.028 & & & \\
\hline 11 & 0.759 & 1.724 & 76.753 & & & \\
\hline 12 & 0.723 & 1.644 & 78.396 & & & \\
\hline 13 & 0.699 & 1.588 & 79.984 & & & \\
\hline 14 & 0.670 & 1.522 & 81.506 & & & \\
\hline 15 & 0.630 & 1.432 & 82.938 & & & \\
\hline 16 & 0.626 & 1.424 & 84.362 & & & \\
\hline 17 & 0.592 & 1.346 & 85.708 & & & \\
\hline 18 & 0.540 & 1.227 & 86.936 & & & \\
\hline 19 & 0.522 & 1.187 & 88.123 & & & \\
\hline 20 & 0.480 & 1.091 & 89.214 & & & \\
\hline 21 & 0.473 & 1.075 & 90.289 & & & \\
\hline 22 & 0.438 & 0.995 & 91.284 & & & \\
\hline 23 & 0.401 & 0.911 & 92.196 & & & \\
\hline 24 & 0.384 & 0.872 & 93.068 & & & \\
\hline 25 & 0.365 & 0.828 & 93.896 & & & \\
\hline 26 & 0.355 & 0.808 & 94.704 & & & \\
\hline 27 & 0.345 & 0.784 & 95.488 & & & \\
\hline 28 & 0.291 & 0.661 & 96.148 & & & \\
\hline 29 & 0.261 & 0.594 & 96.742 & & & \\
\hline 30 & 0.230 & 0.522 & 97.264 & & & \\
\hline 31 & 0.203 & 0.462 & 97.726 & & & \\
\hline 32 & 0.180 & 0.409 & 98.135 & & & \\
\hline 33 & 0.170 & 0.387 & 98.523 & & & \\
\hline 34 & 0.155 & 0.353 & 98.876 & & & \\
\hline 35 & 0.126 & 0.287 & 99.162 & & & \\
\hline 36 & 0.121 & 0.274 & 99.437 & & & \\
\hline 37 & 0.083 & 0.189 & 99.626 & & & \\
\hline 38 & 0.065 & 0.147 & 99.773 & & & \\
\hline 39 & 0.040 & 0.091 & 99.864 & & & \\
\hline 40 & 0.035 & 0.080 & 99.943 & & & \\
\hline 41 & 0.021 & 0.047 & 99.990 & & & \\
\hline 42 & 0.004 & 0.008 & 99.998 & & & \\
\hline 43 & 0.001 & 0.002 & 100.000 & & & \\
\hline 44 & 0.000 & 0.000 & 100.000 & & & \\
\hline
\end{tabular}

\subsubsection{Phase 3: Stress and Goodness of Fit}

The goodness of fit of the multidimensional scaling (MDS) results was shown by stress values and squared correlation (r-squared), as displayed in Table 2 and Figure 5. In order to select the best fitting model data, the fit values of stress and R-squared were examined. The stress in three dimensions for the output shown in Figure $5 \mathrm{a}$ ) is 0.288 . MDS literature suggests lower stress values are preferred and reflect better congruence between the raw data and the processed data (Davison 1983; Kruskal 1964). The stress values found in the dataset are typically higher than those recommended in the literature on MDS. Several reasons for the discrepancy have been presented by Trochim (1993) and Kane and Trochim (2007). The r-squared ( ) against dimension is plotted to assist us in choosing the best dimensions. Figure $5 \mathrm{~b}$ shows that as the number of dimensions increases from three to four, $r$-square values observed converge and begin to level off. The three dimensions squared correlation (r-squared) value (0.928) approaching $1(100 \%)$ indicates that the MDS 
model can be said to be good (Redell 2019; Seok 2009). This study found that the three-dimensional solution was the appropriate model for the card sorting datasets.

Table 2: The numerical fit indexes.

\begin{tabular}{|lll|}
\hline Number of dimensions & Stress & r-squared \\
\hline 1 & 0.495 & 0.839 \\
\hline 2 & 0.345 & 0.903 \\
\hline 3 & 0.288 & 0.928 \\
\hline 4 & 0.253 & 0.929 \\
\hline
\end{tabular}

\subsubsection{Phase 3: Hierarchical Clustering Method - 3D Cluster View (3DCV) analysis}

To establish whether the participants' underlying structure supported the theoretical grouping, we subjected the similarity matrix in Figure 2 to hierarchical cluster analysis. Hierarchical cluster analysis arranges objects (in this case, challenges) into relatively homogeneous groups (Aldenderfer and Blashfield 1984; Antonenko et al. 2012), thus allowing researchers to recognise the commonalities and distinctions relevant to the participant group as a whole. An agglomerative clustering method was selected, whereby the most similar challenges (in this study) were successively merged to produce non-overlapping hierarchically clusters of increasing inclusiveness (Davidson and Ravi 2009; Zhao and Karypis 2005). The average linkage rule (Sokal and Michener 1958), also referred to as the within-group linkage method, was used. This rule joins the two most similar cards together in a cluster and then calculates the average similarity of a card with all other cards within and outside the cluster. A card only joins a cluster if a given level of overall similarity is achieved.

The 3DCV is utilised to visualise the data in Figure 2 and Figure 3 more clearly. The main output is a 3Dplotted, which graphically represented how the 44 challenges group into hierarchical clusters. This method reduces the difficulty in interpreting a plot that contains too much data, long labels, and inconsistent patterns. Figure 6 shows seven group of challenges as proposed by 3DCV method from the dataset given in Figure 2, with each cluster shown in different colours. Each point in the visualisation represents a distinct challenge. Challenges that are closer together were more frequently sorted into the same category. Polygons show the group of challenges that are clustered together. Each of these groups can be interpreted as a potential category within an IA. Placing the cursor over any colour ballpoint will highlight the card name that the ballpoint represents. As shown at the bottom right-hand side of Figure 6, the category labels and the challenge names will be highlighted when the cursor is placed over any polygon. To reduce this complex representation to a more simplified and meaningful solution, we also visually inspected it, to determine the 
number of clusters at each polygon shown in Figure 6. We then interpreted the clusters produced at each polygon shown in Table 3.

Figure 7 presents a bar graph of Figure 6 to show the number of cards in each cluster for clear visualisation. The bar graph reveals the hidden meaning of the challenges in each category. The number of cards indicates how serious the challenges are, meaning that most students encountered a learning challenge during COVID19. The higher the number of cards in a cluster, the more frequently the challenge is being faced by students during the COVID-19 crisis. The two category names that contain the highest number of cards are financial issues and students' motivational challenges. This indicates that the majority of students have considered their 'financial hardship' and motivation as major causes of their challenges during the emergency shift. The seven category names are related to each other. In the next section a second data collection method of online questionnaire has been applied to rate the category names.

\section{Questionnaire}

The second part of the research methodology is an online questionnaire provided to the 32 participants. Since, this is the first study done on the use of card sorting and the students' challenges during the covid-19, the authors decided to use an online questionnaire to collect the data to identify how the 7 challenges (Figure 5 and 6 and Table 2) were rated by participants. Using online questionnaire methodology enabled the authors to collect information regarding the students' attitude and satisfaction in naming the seven challenges for their learning. The students were given an online questionnaire which was designed using a 7-points in descending order. The question is "Rate the 7 challenges from the highest to least challenges, that is, top challenge $=1$ and least challenge $=7$. The authors then administered the questionnaire to the participanrs who were participated in the study.

The email distribution was used to inform the 32 participants about the questionnaire. The questionnaire was open to students for one week. A student took a maximum time of seven minutes to fill in the questionnaire. The students' responses to the online questionnaire were automatically saved in author's email. The participant's responses were confidential. All responses were compiled and analysed as a group. The participants' details were kept anonymous and the responses were only used for analysis purpose. The simplified solution to the participants' classification is displayed in Table 3. The table also lists the most prototypical challenges from highest level category.

\section{Findings And Discussion}

The key findings from card sorting analysis are presented in Table 3 with the primary level group number in the first column, group labels in the second column, proposed group label in the third column and the list of card challenges in the final column. For instance, row 1 of Table 3 shows that $82 \%$ of participants label primary level Group 1 'financial issues', $80 \%$ label it 'challenges with rolling expenses', and $78 \%$ label it 'family financial background'. This result suggests that 'financial hardship' can be the proposed category label for primary level Group 1 as determined by the list of similar related category labels and similar related card challenges displayed in the third column. A similar application can be repeated for the rest of the proposed group labels in Table 2. 
Table 3: The findings from the 3DCV of the dataset in Figure 2.

Page 14/31 


\begin{tabular}{|c|c|c|c|}
\hline $\begin{array}{l}\text { LEVEL } \\
1 \\
\text { GROUP }\end{array}$ & GROUP LABEL & $\begin{array}{l}\text { PROPOSED } \\
\text { GROUP } \\
\text { LABEL }\end{array}$ & CARD NAME \\
\hline $\begin{array}{l}\text { Group } \\
1\end{array}$ & $\begin{array}{l}\text { Similar category labels } \\
\text { Financial issues (82\% ) } \\
\text { Challenges with rolling } \\
\text { expenses (80\%) } \\
\text { Family financial background } \\
(78 \%)\end{array}$ & $\begin{array}{l}\text { Financial } \\
\text { Hardship }\end{array}$ & $\begin{array}{ll}9 \text { Cards } \\
\text { - } & \text { No computer, laptop, or mobile } \\
\text { device at home for online study } \\
\text { - } \quad \text { Cannot afford to buy the textbook } \\
\text { Expensive to buy relevant } \\
\text { - } \quad \text { Hoftware } \\
\text { - Internet price is expensive } \\
\text { - No / Limited money to purchase } \\
\text { internet data } \\
\text { - No access to relevant software } \\
\text { - e.g., Mathematica } \\
\text { No bus fare to go to the } \\
\text { - University campus } \\
\text { No electricity at home }\end{array}$ \\
\hline $\begin{array}{l}\text { Group } \\
2\end{array}$ & $\begin{array}{l}\text { Similar category labels } \\
\text { Challenges faced by students } \\
(60 \%) \\
\text { Improper time management } \\
(55 \%) \\
\text { Can make the student fail the } \\
\text { course }(50 \%)\end{array}$ & $\begin{array}{l}\text { Motivational } \\
\text { challenge }\end{array}$ & $\begin{array}{l}9 \text { Cards } \\
\text { - Clashes between work and online } \\
\text { learning schedules } \\
\text { - Don't like online tutorials and online } \\
\text { lectures } \\
\text { - No attendance in tutorial and lab } \\
\text { makes students lazy } \\
\text { - No partial marks for the working } \\
\text { during online test } \\
\text { - Not working hard enough on } \\
\text { assessment } \\
\text { - Poor time \& workload management } \\
\text { - Studying online alone is challenging } \\
\text { - Time limitation for quizzes and tests } \\
\text { cause frustration } \\
\text { - Too many assessments }\end{array}$ \\
\hline $\begin{array}{l}\text { Group } \\
3\end{array}$ & $\begin{array}{l}\text { Similar category labels } \\
\text { Moodle issues }(71 \%) \\
\text { Challenges in using moodle } \\
(57 \%) \\
\text { Difficulties in moodles } \\
(51 \%)\end{array}$ & $\begin{array}{l}\text { Moodle } \\
\text { Issues }\end{array}$ & $\begin{array}{l}7 \text { Cards } \\
\text { - Don't access to solutions \& past exam } \\
\text { papers on moodle } \\
\text { - No training on how to do online } \\
\text { activities in moodle } \\
\text { - Not familiar or confuse in using } \\
\text { moodle and course shell } \\
\text { - One satellite session a week is not } \\
\text { enough } \\
\text { - Poor quality of audio and } \\
\text { lecture/tutorial videos } \\
\text { - Timing of live sessions not aligned to } \\
\text { regional campuses outside Fiji } \\
\text { - Too many information in the course } \\
\text { shell can cause confusion }\end{array}$ \\
\hline
\end{tabular}




\begin{tabular}{|c|c|c|c|}
\hline $\begin{array}{l}\text { Group } \\
4\end{array}$ & $\begin{array}{l}\text { Similar category labels } \\
\text { F2f interaction issues } \\
(63 \%) \\
\text { Group work issues } \\
(63 \%) \\
\text { Lack of face to face } \\
\text { components }(63 \%)\end{array}$ & $\begin{array}{l}\text { Lack of } f 2 f \\
\text { interaction }\end{array}$ & $\begin{array}{l}7 \text { Cards } \\
\text { - Lack of f2f online assessments e.g., } \\
\text { online group work } \\
\text { - Limited opportunity to interact f2f } \\
\text { with peers to succeed in the unit } \\
\text { - Easy to get solutions to quizzes and } \\
\text { tests on the internet } \\
\text { - Lack of student engagement in } \\
\text { learning activities } \\
\text { - No group work incorporated in online } \\
\text { - } \text { learning and assessments } \\
\text { - wo study buddy or partner to study } \\
\text { - Struggle to understand math } \\
\text { activities and tricky tutorial questions } \\
\text { provided online }\end{array}$ \\
\hline $\begin{array}{l}\text { Group } \\
5\end{array}$ & $\begin{array}{l}\text { Similar category labels } \\
\text { Teaching staff Issues } \\
(83 \%) \\
\text { Tutor problem }(67 \%) \\
\text { Tutor Short fall }(67 \%)\end{array}$ & $\begin{array}{l}\text { Problem } \\
\text { with course } \\
\text { delivery }\end{array}$ & $\begin{array}{l}6 \text { Cards } \\
\text { - Typos in lecture notes and examples } \\
\text { and solutions having errors cause } \\
\text { confusion } \\
\text { - Lack of mathematics examples from } \\
\text { the Pacific context } \\
\text { - Lack of personal assistance from } \\
\text { teaching staff } \\
\text { - No tutors available weekly for } \\
\text { regional students } \\
\text { - Poor communication and feedback } \\
\text { from staff } \\
\text { - Tutors are less active in the online } \\
\text { activities }\end{array}$ \\
\hline $\begin{array}{l}\text { Group } \\
6\end{array}$ & $\begin{array}{l}\text { Similar category labels } \\
\text { Internet challenges }(100 \%) \\
\text { Resources accessibility } \\
(80 \%) \\
\text { Internet issues }(67 \%)\end{array}$ & $\begin{array}{l}\text { Internet } \\
\text { challenge }\end{array}$ & $\begin{array}{l}4 \text { Cards } \\
\text { - A poor internet connection and poor- } \\
\text { quality internet } \\
\text { - Difficulty in downloading large videos } \\
\text { file size } \\
\text { - No access to the computer labs } \\
\text { - Staying in remote locations \& cannot } \\
\text { use the internet every time for } \\
\text { studying }\end{array}$ \\
\hline $\begin{array}{l}\text { Group } \\
7\end{array}$ & $\begin{array}{l}\text { Similar category labels } \\
\text { Home disturbance because of } \\
\text { high number of family members } \\
(100 \%) \\
\text { Family issues }(50 \%)\end{array}$ & $\begin{array}{l}\text { Home } \\
\text { disturbances }\end{array}$ & $\begin{array}{l}2 \text { Cards } \\
\text { - No functional space at home to study } \\
\text { - Personal disturbances - e.g., big } \\
\text { family, caring for children, church \& } \\
\text { work commitments }\end{array}$ \\
\hline
\end{tabular}

Table 4: The findings from the participant's response to the questionnaire. 


\begin{tabular}{|llllllll|}
\hline Rate & $\begin{array}{l}\text { 1-top } \\
\text { challenge }\end{array}$ & 2 & 3 & 4 & 5 & 6 & $\begin{array}{l}7 \text { - least } \\
\text { challenge }\end{array}$ \\
\hline Challenge & $\begin{array}{l}\text { Financial } \\
\text { Hardship }\end{array}$ & $\begin{array}{l}\text { Motivation } \\
\text { Challenge }\end{array}$ & $\begin{array}{l}\text { Moodle } \\
\text { Issues }\end{array}$ & $\begin{array}{l}\text { Lack of } \\
\text { f2f } \\
\text { interaction }\end{array}$ & $\begin{array}{l}\text { Problem } \\
\text { with } \\
\text { course } \\
\text { delivery }\end{array}$ & $\begin{array}{l}\text { Internet } \\
\text { challenge }\end{array}$ & $\begin{array}{l}\text { Home } \\
\text { disturbances }\end{array}$ \\
$\begin{array}{l}\text { Rate per } \\
\text { cent }\end{array}$ & 59.4 & 53.1 & 59.4 & 50 & 48.9 & 56.3 & 75 \\
$\begin{array}{l}\text { Number of } \\
\text { participants }\end{array}$ & 19 & 17 & 19 & 16 & 15 & 18 & 24 \\
\hline
\end{tabular}

Since the research sets out to understand first-year mathematics students' learning challenges during the unexpected shift from f2f to ERT, this section discusses participants' findings against the literature in order of the seven categories of challenges presented in Tables 3 and 4. The primary purpose of Table 3 is to show how the participants rated the category names that they found affecting their studies the most during the shift. As seen in Table 4, financial hardship is the biggest challenge and the home disturbance is the least challenge during the unexpected shift from f $2 \mathrm{f}$ to ERT. Table 4 is also reflected the hidden meaning showing in Figure 7. The number of cards indicates how serious the challenges are, meaning that most students encountered a learning challenge during COVID-19. The higher the number of cards in a cluster, the more frequently the challenge is being faced by students during the COVID-19 crisis.

\subsection{Financial hardship}

Financial hardship is one of the major challenges faced by the majority of participants during the COVID-19 lockdown. The findings indicate the effects of job displacement on students' financial situation during an emergency. As reported, domestic workers have suffered from job loss and/or a drop in working hours as one of the negative impacts of COVID-19 (International Labour Organisation, 2020). The issues of parental unemployment and job displacement during COVID-19 have put many families around the world in financial crisis, making it very difficult for them to take care of everyday needs including education. It is evident in this study that participants have identified financial difficulties as the leading cause of their learning challenges which inter alia lead to human stress during COVID-19.

\subsection{Motivational challenge}

Studying from home commonly requires greater self-discipline and motivation to follow through online lessons, particularly in the earlier period when students are getting used to the new system, which might affect the feeling of an increase in study obligations. On the other hand, lecturers' unfamiliarities and incompetencies with the new mode of delivery could overload their students with study materials and assignments adding to the demotivate students feeling toward the course (Aristovnik et al. 2020). An emergency switch from f2f to ERT makes the learning experience entirely different and challenging to 
maintain intrinsic motivation in students which is even more pronounced in mathematics learning environment The list of challenges that participants did consider under this category has highlighted the importance of putting an effective learning support system in place and the importance of protecting participants' motivation and willingness to learn during a pandemic crisis. Self-motivation is an indispensable requirement for online learning; however, it seems to be absent from many online students which is a commitment to be fulfilled by the institution (Bozkurt and Sharma 2020). Also many online students feel disconnected to their studies (Choudhury and Pattnaik 2020). After shifting to ERT, many students fall behind and give up as problems in handling a technological medium also seem difficult due to the lack of relevant ICT competencies (Aguliera and Nightingale-Lee 2020; Reddy et al. 2020). Therefore, the attitude change and technological literacy would help them gain confidence in order to succeed in their ERT courses with a lively atmosphere.

\subsection{Moodle issues}

The effectiveness of online learning depends on the designed and prepared learning material, the lecturer's engagement in the online environment, and lecturer-student and/or student-student interactions (e.g., Bao 2020; Wu and Liu 2013). In consideration of the list of challenges compiled by participants under this category, it suggests that without having a proper design of the moodle page and a proper training of the moodle page with students-lecturers as end users, the full potential and purpose of establishing such a platform cannot be reached, hence having negative impacts on students' success. The majority of participants believe that poor audio and lecture/tutorial videos as well as too much information in the course shell can cause confusion. The challenge of writing mathematics online using moodle features is still huge, and the option of alternatives such as uploading snapshots of write-ups is also not feasible keeping in mind the intermitant internet facilities and costly mobile data during emergencies and crises in the South Pacific.

Arguably, moodle is expected to be a friendly learning environment for students, teachers and course instructors to develop, disseminate learning materials, and share knowledge through multiple online activities such as forums and chats (Kumar et al., 2020; Sharma 2020). The authors' experience has confirmed the need for moodle designers to measure usability because it determines the moodle's success based on students' learning needs. Many teachers have no previous experience in online teaching and although teachers received various types of training during the outbreak, the short-term effects of such training remains arguably minimal. Therefore, the instructor and students should be aware of both the advantages and potential pitfalls of using the latest technological advances like moodle during the shift to ERT.

\subsection{Lack of $2 \mathrm{f} 2$ interaction}

There is broad agreement that teachers play a key role in providing high-quality learning opportunities to students and fostering students' learning (e.g., König et al. 2021). Most HEl in the Pacific region rely heavily on $\mathrm{f} 2 \mathrm{f}$ mode for sharing and distributing knowledge, hence, the capacity of the institution to handle the circumstances of unprecedented change to ERT can be a real challenge. For instance, the majority of participants believe that lack of $\mathrm{f} 2 \mathrm{f}$ learning interactions and assessment strategies can make things hard for 
them to succeed during the ERT. Similarly, educators found that a lack of student f2 $f$ engagement is a primary problem that can cause distraction in effective learning. To overcome this inadequacy, a range of $\mathrm{f} 2 \mathrm{f}$ learning support systems should put in place to improve students' interest in emergency online learning. This includes visual communication such as video group discussion, live and recorded tutorials; strengthen the insitution's online learning culture and policies; and allowing academics to be heavily involved in facilitating effective online learning activities that have direct positive impacts on students (Beetham and Sharpe 2007).

\subsection{Problem with course delivery}

Participants were concerned with the lack of support from teaching staff during the ERT, which can link to the delivery mode's remote nature. This includes little time for inter-personal, poor communication, and being less active in the online activities. Such challenges imply a specific pedagogical content knowledge associated with the designing and organising of healthier learning experiences and distinctive learning environments with the help of digital technologies. The pedagogical readiness of university teachers who have little experience in online teaching has become an integral part of any virtual learning. As reported, some of the main difficulties facing university teachers concerning web-based courses arise from the complexity of the instructional situation and shortcomings in planning and organisation (Ching et al. 2018; Ocak 2011).

\subsection{Internet challenge}

The sudden closing-off of face-to-face educational work, in response to the COVID-19 pandemic, gave teachers and students a strong sense of the difference between $f 2 f$ and ERT, arguing that online learning can work more effectively in digitally developed countries (Basilaia \& Kvavadze, 2020) such as the United States of America and not in most developing countries. In the Pacific Island countries, online learning (as well as blended learning) is sometimes ineffective due to the lack of access to fast, affordable and reliable internet connections (Reddy et al., 2020; Sharma et al., 2020) or even a lack of electricity. This hinders the process of online learning, especially for those who are living in rural as well as marginalised communities (Aristovnik et al. 2020; Wains and Mahmood 2008). Students who access the internet through smartphones are sometimes powerless to take advantage of online learning because a vital amount of online content is not accessible via smartphones. Low-income families mean that access to the internet is occasional provides poor internet connection and poor-quality internet.

\subsection{Home disturbances}

Due to the COVID-19 lockdown, students were required to study from home at the time of social distancing and lockdown. Students had no choice but to accept this unprecedented change in response to fight against the spread of the virus. The challenges under this category reveal that study from home during an emergency or crisis would be much more difficult and challenging for students who live in villages, extended families and crowded houses without any study-friendly environment. This is a common situation with Pacific students and families from the rural and low socio-economic backgrounds. Therefore the availability of 
different kinds of home infrastructure is needed to ensure efficient study. The potential solutions for all the seven challenges emerged from this study based on participants' card sorting findings are demonstrated in Figure 7.

\section{Potential Solutions For Students' Challenges}

The novel seven categories of challenges articulated in this research give direction to the types of support that are relevant for addressing issues as a basis for participants' success in the sudden shift to ERT during the emergency and crisis of COVID-19. Figure 8 presents two heptagons with the top outlining the seven challenges and the bottom presenting the potential solutions. The colour is used to identify the patterns of relationship between the two pentagons. For instance, the 'financial hardship' challenge in the top heptagon and the potential solution 'provide financial support' in the bottom heptagon are both coloured in light black to show their relationships. While the model governs the challenges and potential solutions for students studying mathematics, it is equally relevant to students from other disciplines.

When we look at these major categories from an affirmative perspective, it means that the institution's level of preparedness during the ERT must be strengthened. For instance, in terms of 'financial hardship', the findings indicate that the institution must be ready to compensate students' internet and technological needs in an emergency. As witnessed in this study, participants considered 'financial hardship' and 'motivational challenge' as the lead causes of their learning challenges during the erupted shift to ERT due to COVID-19. It emphasises the need to improve the affordability and availability of free access to learning support during the financial and psychological crisis of a pandemic. The findings also reinforce the significant role of moodle literacy, $\mathrm{f} 2 \mathrm{f}$ interaction, quality course delivery, quality internet network access, and having a friendly learning environment at home to participants' success. Figure 8 highlights a new learning support model designed from the insights of the findings of this research.

The model suggests that the appropriate way to support first-year Pacific mathematics students learning challenges during any crisis or emergency must be understood from the dynamic interplay between their finances, motivation, online learning literacies, $f 2 f$ interpersonal interaction, course delivery, internet access, and home environment within a given socio-cultural learning context. This leads to the understanding that participants' learning challenges are a complex system, meaning that participants' learning challenges during ERT is made up of different related parts that must be understood within the socio-cultural context in which it is understood and experienced. As demonstrated by bottom heptagon of Figure 8, participants' challenges can be appropriately addressed in a more interconnected and multidimensional system, It means that people within the respective context, whether at home or in $\mathrm{HEI}$, should be the catalyst for change and driver of students' success during the pandemic crisis and emergencies.

\section{Conclusion}

Overall, this study shows that the unexpected shift from f2f to ERT due to COVID-19 has affected first-year mathematics students to experience a range of challenges including financial hardship, motivational challenge, moodle issue, lack of $\mathrm{f} 2 \mathrm{f}$ interaction, course delivery problem, internet challenge, and home disturbances. These findings emphasise that if these students' challenges are not fully understood in the 
context of their own socio-cultural contexts, it may erode their motivation and confidence which can impact their overall academic performance. The paper's arterial strength lies in its ability to effectively introduce card sorting in the field of educational research as a provider of new learning analytics for quality learning in mathematics and desirable learning outcomes from a range of known and unknown inputs.

The use of card sorting, for the first time, to explore the topic adds new insights into the literature on the important connection between card sorting, $\mathrm{HEl}$, mathematics, quality learning, and student retention during a crisis or emergency such as COVID-19 pandemic. Findings from this study also offer, for the first time, a contribution to the understanding of the challenges faced by first-year Pacific mathematics students as a complex system within a given socio-cultural learning context. This provides a fresh perspective into the complex way in which first-year mathematics students operate in their own Pacific learning contexts in a given pandemic. In particular, the combination of students' social and cultural learning backgrounds together with the institution's learning support system must go hand in hand for best results. The study highlights the significance of using card sorting as a new methodology in the field of educational research to understand the students' challenges from their own perspectives and to design a more student-oriented learning support model for emergencies and crises. From a wider perspective, the unique methodology has a good scope in the field of educational research and can be utilised in a number of areas such as design of online courses and other contextualised learning resources and support models.

The findings from this study would benefit our understanding of the challenges faced by first-year mathematics students at a HEl in the Pacific. It highlights the need for more in-depth future exploration of the seven aspects of the Pacific learning support system proposed in the study. Such a study can explore and evaluate each challenge's main causes and discovery measures from students' own perceptions and experiences. The use of Pacific research approaches, such as 'talanoa' (talking) (Paea et al. 2020) can produce a lot of rich and deep knowledge about the research topic using qualitative data. An extension of the research setting to the wider Pacific region via the USP's regional campuses would enhance understanding the topic from the dynamic nature of the South Pacific cultural diversity.

\section{Declarations}

\section{Data availability statement}

The datasets produced for this study are available on request to the corresponding author.

\section{Author Contributions}

The authors of this paper who agreed to be accountable for all aspects of this study in confirming that questions related to the accuracy or integrity of any part of the work are appropriately investigated and resolved honesty. We provided substantial contributions to the design of this study, clarifying and interpretation of the data, and revised it critically for intellectual content.

\section{Funding}

Funding information is not applicable / No funding was received. 


\section{Conflict of interest}

The authors declare that they have no conflict of interest

\section{Acknowledgments}

A special thank goes out to all participants who have offered their contribution to this study. Thank you for sharing your time and experience. We also thank Andrew Mayfield and Optimal Workshop (http://www.optimalworkshop.com) for allowing this work to use their algorithms.

\section{References}

Affouneh, S., Salha, S., N., \& Khlaif, Z. (2020). Designing quality e-learning environments for emergency remote teaching in coronavirus crisis. Interdisciplinary Journal of Virtual Learning in Medical Sciences, 11(2), $1-3$.

Aguliera, E., \& Nightingale-Lee, B. (2020). Emergency remote teaching across urban and rural contexts: Perspectives on educational equity. Information and Learning Sciences, 121(5), 471-478.

Aldenderfer, M. S., \& Blashfield, R. K. (1984). Cluster analysis. Newbury Park, CA: Sage.

Antonenko, P. D., Toy, S., \& Niederhauser, D. S. (2012). Using cluster analysis for data mining in educational technology research. Educational Technology Research and Development, 60(3), 383-398.

Aristovnik, A., et al. (2020). Impacts of the COVID-19 pandemic on life of higher education students: A global perspective. Sustainability, 12(20), 8438. https://doi. org/10.3390/su12208438

Bao, W. (2020). COVID-19 and online teaching in higher education: A case study of Peking University. Hum Behav \& Emerg Tech, 2(2), 113-115.

Basilaia, G., \& Kvavadze, D. (2020). Transition to online education in schools during a SARS-CoV-2 coronavirus (Covid-19) pandemic in Georgia. Pedagogical Research, 5(4), 1-9.

Beaven, T., Hauck, M., Comas-Quinn, A., Lewis, T., \& de los Arcos, B. (2014). MOOCs: Striking the right balance between facilitation and self-determination. MERLOT Journal of Online Learning and Teaching, 10(1), 31-43.

Beetham, H., \& Sharpe, R. (2007). Rethinking pedagogy for a digital age: Designing and delivering e-learning. London, England: Routledge.

Bennett, S., Agostinho, S., \& Lockyer, L. (2017). The process of designing for learning: Understanding university teachers' design work. Educational Technology Research and Development, 65, 125-145.

Blum-Smith, S., Yurkofsky, M. M., \& Brennan, K. (2020). Stepping back and stepping in: Facilitating learnercentered experiences in MOOCs. Computers \& Education, 160(2021), 104042. 
Bozkurt, A., \& Sharma. R. C. (2020). Emergency Remote Teaching in a Time of Global Crisis Due to CoronaVirus Pandemic. Asian Journal of Distance Education, 15(1), i-vi.

Cattell, R.B., 1966. The scree test for the number of factors. Multivariate Behavioral Research 1, 245-276.

Ching, Y.-H., Hsu, Y.-C., \& Baldwin, S. (2018). Becoming an online teacher: an analysis of prospective online instructors' reflections. Journal of Interactive Learning Research. 29(2), 145-168.

Choudhury, S., \& Pattnaik, S. (2020). Emerging themes in e-learning: A review from the stakeholders' perspective. Computers \& Education, 144, 1-20.

Ćukušić, M., Garača, Ž., \& Jadric, M. (2014). Online self-assessment and students' success in higher education institutions. Computers \& Education, 72 (2014), pp. 100-109.

Davison, M. L. (1983). Multidimensional scaling, New York, NY: John Wiley and Sons.

Davidson I, Ravi S (2009) Using instance-level constraints in agglomerative hierarchical clustering: theoretical and empirical results. Data Min and Knowl Discov 18:257-282

Gikandi, J. W., Morrow, D., \& Davis, N. E. (2011). Online formative assessment in higher education: a review of the literature. Computers \& Education, 57(4), 2333-2351.

Haavind, S., \& Sistek-Chandler, C. (2015). The emergent role of the MOOC instructor: A qualitative study of trends toward improving future practice. International Journal on E-Learning, 14(3), 331-350.

Hodges, C., Moore, S., Lockee, B., Trust, T., \& Bond, A. (2020). The difference between emergency remote teaching and online learning. Educause Review.

Kali, Y., Goodyear, P., \& Markauskaite, L. (2011). Researching design practices and design cognition: contexts, experiences and pedagogical knowledge-in-pieces. Learning, Media and Technology, 36(2), 129-149.

Kane, M., \& Trochim, W. M. K. (2007). Concept mapping for planning and evaluation. Thousand Oaks, CA: sage Publications.

Karakaya, K. (2020). Design considerations in emergency remote teaching during the COVID-19 pandemic: a human-centered approach. Educational Technology Research and Development, 1-5.

Katsanos, C., Tselios, N., Avouris, N., Demetriadis, S., Stamelos, I., \& Angelis, L. (2019). Cross-study Reliability of the Open Card Sorting Method. CHI., 1-6.

Katsanos, C., Tselios, N., \& Avouris, N. (2008). Automated semantic elaboration of web site information architecture. Interacting with Computers, 20, 535-544.

König, J., Cai, J., Blomeke,S., Jentsch, A., Schlesinger, L., Nehls, C., Musekamp, F., \& Kaiser, G. (2021). The links between pedagogical competence, instructional quality, and mathematics achievement in the lower secondary classroom. Educational Studies in Mathematics. https://doi.org/10.1007/s10649-020-10021-0 
Kruskal, J. B. (1964). Multidimensional scaling by optimising goodness of fit to a nonmetric hypothesis. Psychometrika, 29(1), 1-27.

Kumar, K., Sharma, B., J. Khan, G., Nusair, S., \& Raghuwaiya, K. A. (2020). An exploration on effectiveness of anonymous peer assessment strategy in online formative assessments. Paper presented at the IEEE Frontiers of Education 2020, Uppsala, Sweden.

Lloyd, D., Dykes, J., \& Radburn, R. (2007). Mediating geovisualization to potential users and prototyping a geovisualization application. Proceedings of GIS Research UK, (pp. 9-16).

Mohmmed, A, Khidhir B, Nazeer, A, Vijayan V. (2020). Emergency remote teaching during Coronavirus pandemic: the current trend and future directive at Middle East College Oman. Nature Public Health Emergency Collection, 5(3), 1-11.

Mulenga, E. M., \& Marbán, J. M. (2020). Is COVID-19 the Gateway for Digital Learning in Mathematics Education?. Contemporary Educational Technology, 12(2), 1-11.

Ocak, M. A. (2011). Why are faculty members not teaching blended courses? Insights from faculty members. Computers \& Education., 56(3), 689-699. https://doi.org/10.1016/j.compedu.2010.10.011.

Optimal Workshop (http://www.optimalworkshop.com).

Paea, S., \& Baird, R. (2018). Information Architecture (IA): Using Multidimensional Scaling (MDS) and KMeans Clustering Algorithm for Analysis of Card Sorting Data. Journal of Usability Studies, 13(3), 138-157.

Paea, S., Havea, R., \& Paea, M. K. (2020). Chapter 6 Card Sorting: A practical guidance from a Pacific perspective. In M. 'Otunuku, S. Johansson Fua, \& R. Toumu'a (Eds.), It takes an island and an ocean.

Reddy, P., Sharma, B., \& Chaudhary, K. (2020). Measuring the digital competency of freshmen at a higher education institute, In Proceedings of the 23rd Pacific Asia Conference on Information Systems (PACIS2020),AIS, Dubai, UAE.

Redell, N. (2019). Shapley Decomposition of R-Squared in Machine Learning Models. arXiv preprint arXiv:1908.09718.

Righi, C., James, J., Beasley, M., Day, D. L., Fox, J. E., Gieber, J., \& Ruby, L. (2013). Card sort analysis best practices. Journal of Usability Studies, 8(3), 69-89.

Rosas, S. R., \& Kane, M. (2012). Quality and rigor of the concept mapping methodology: a pooled study analysis. Eval Program Plann, 35, 236-45..

Schwartz, A. M., Wilson, J. M., Boden, S. D., Moore Jr, T. J., Bradbury Jr, T. L., \& Fletcher, N. D. (2020). Managing resident workforce and education during the COVID-19 pandemic: evolving strategies and lessons learned. JBJS Open Access 5, e0045. 
Seok, Soonhwa. 2009. Item validation of online postsecondary courses: rating the proximity between similarity and dissimilarity among item pairs (Validation study series I: multidimensional scaling). Educational Technology Research and Development, 57:25-43.

Sharma, B., Reddy, E., Naseem, M., and Nand, R. (2020). Effectiveness of Online Presence in a Blended higher learning Environment in the Pacific, Studies in Higher Education, 45:8, 1547-1565.

Shulman, L. (1987). Knowledge and teaching: foundations of the new reform. Harvard Educational Review, $57,1-22$.

Sokal, R. R., \& Michener, C. D. (1958). A statistical method for evaluating systematic relationships. University of Kansas Scientific Bulletin, 38, 1409-1438.

Steele, J., Holbeck, R., \& Mandernach, J. (2019). Defining effective online pedagogy. Journal of Instructional Research, 8(2), 5-8.

Thomas Tullis and Larry Wood. 2005. How many users are enough for a card-sorting study? Presented at UPA 2004.

Tondeur, J., Scherer, R., Siddiq, F., \& Baran, E. (2020). Enhancing preservice teachers' technological pedagogical content knowledge (TPACK): A mixed method study. Educational Technology Research and Development, 68(1), 319-343.

Trochim, W. M. K. (1993). The reliability of concept mapping. Paper presented at the Annual Conference of the America Evaluation Association.

Trust, T., \& Whalen, J. (2020). Should teachers be trained in emergency remote teaching? Lessons learned from the COVID-19 pandemic. Journal of Technology and Teacher Education, 28(2), 189-199.

Tullis, T. \& Wood, L. (2004). How many users are enough for a card-sorting study? In the proceedings of Usability Professionals Association Conference. Minneapolis, MN.

Wains, S. I., \& Mahmood, W. (2008). Integrating m-learning with e-learning. In Proceedings of the 9th ACM SIGITE Conference on Information Technology Education, 31-38.

West, R. E., Sansom, R., Nielson, J., Wright, G., Turley, R. S., Jensen, J., \& Johnson, M. (2020). Ideas for supporting student-centered stem learning through remote labs: A response. Educational Technology Research and Development, 69:263-268.

Wood, J. R., \& Wood, L. E. (2008). Card sorting: current practices and beyond. Journal of Usability Studies, $4(1), 1-6$.

Wu, J., \& Liu, W. (2013). An Empirical Investigation of the Critical Factors Affecting Students' Satisfaction in EFL Blended Learning. J. Lang. Teach. Res, 4, 176-185. 
Zhao Y, Karypis G (2005) Hierarchical Clustering Algorithms for Document Datasets. Data Mining and Knowledge Discovery 10(2):141 - 168.

Zilka, G. C., Cohen, R., \& Rahimi, I. D. (2018). Teacher presence and social presence in virtual and blended courses. Journal of Information Technology Education: Research, 17, 103-126.

\section{Figures}

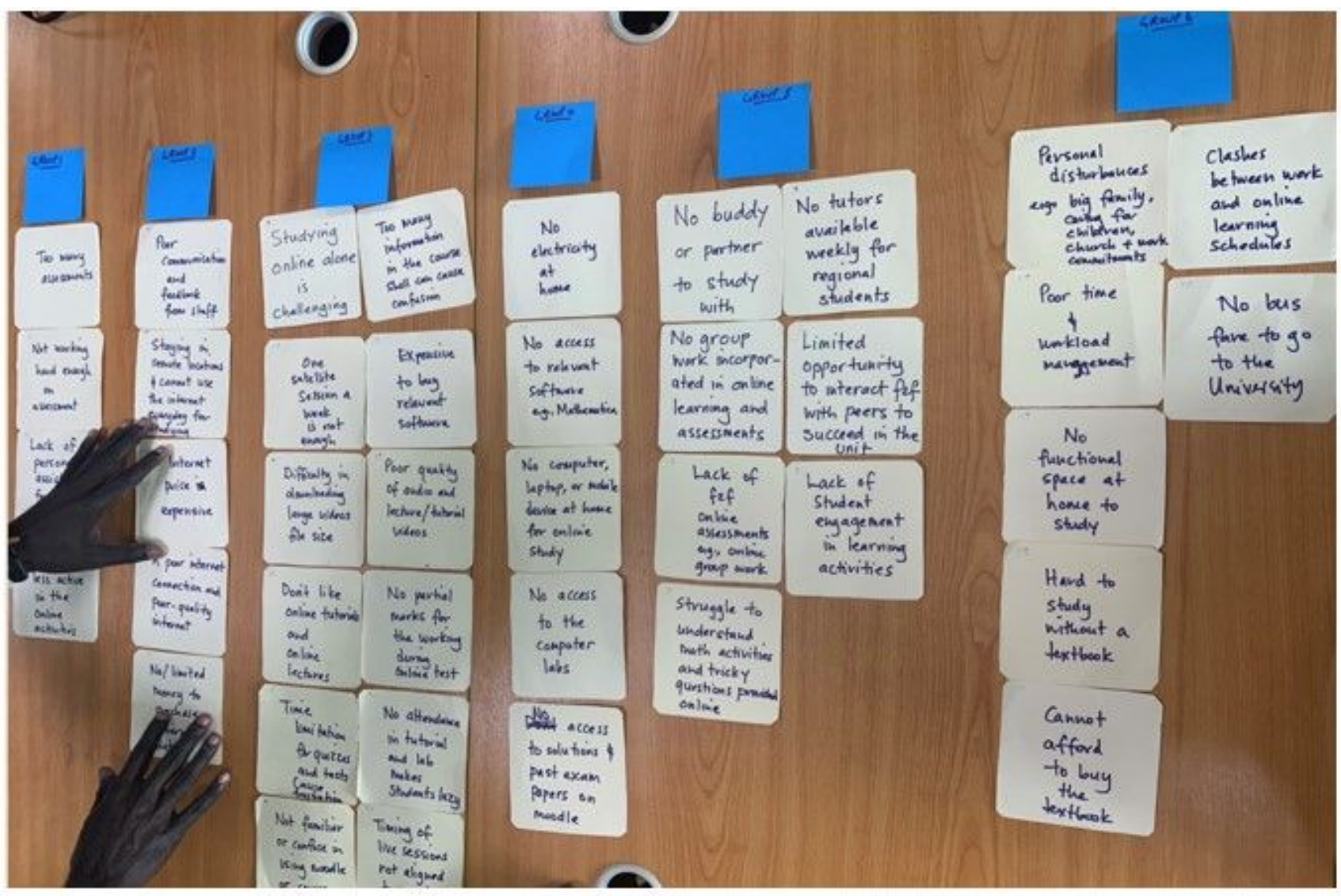

Figure 1

Participant pathway through f2f OCS with physical cards in real-time. 


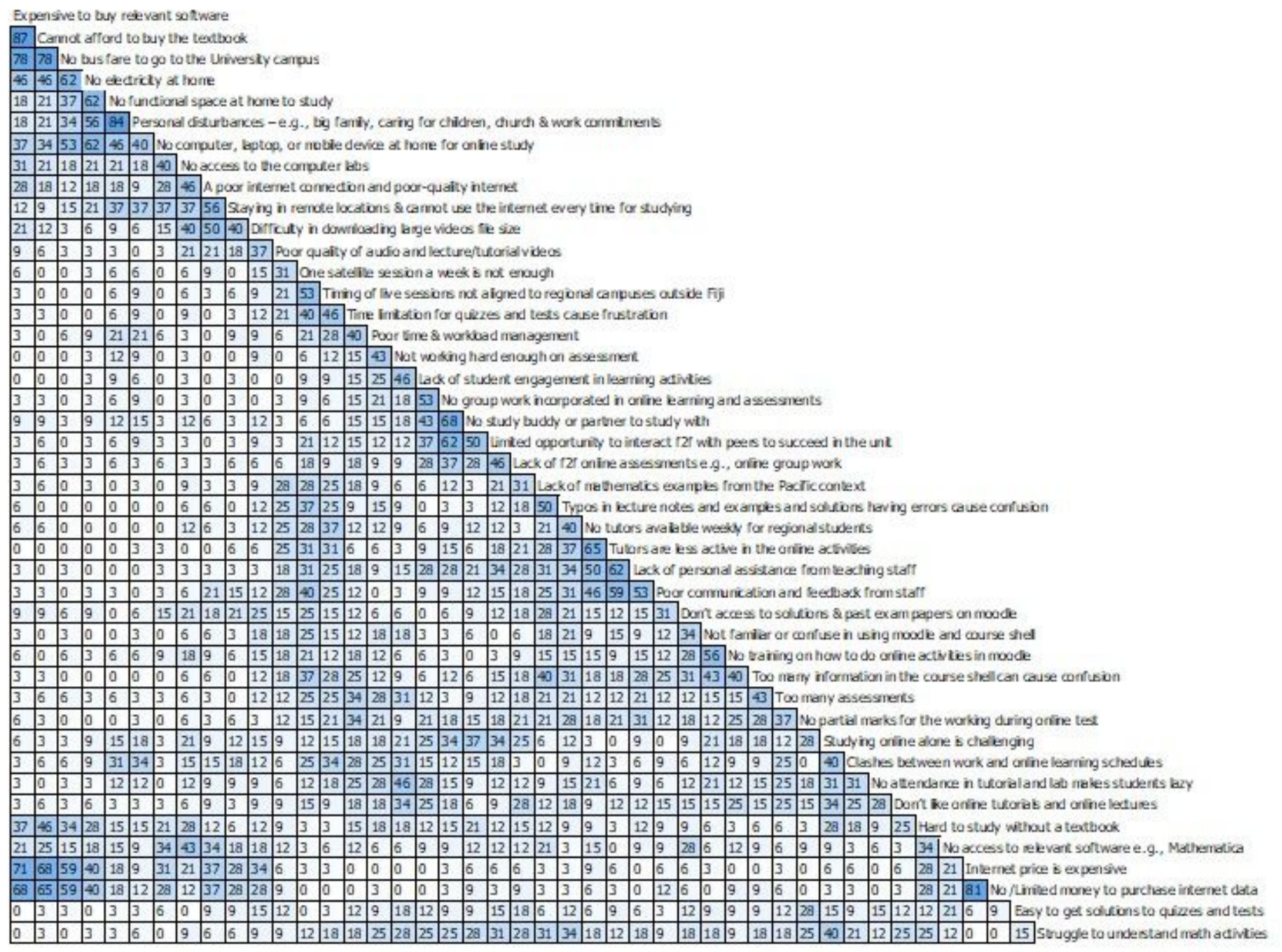

\section{Figure 2}

The similarity matrix displays how many participants agree with each pair combination of cards. The algorithm attempts to cluster similar cards along the right edge of the matrix. 


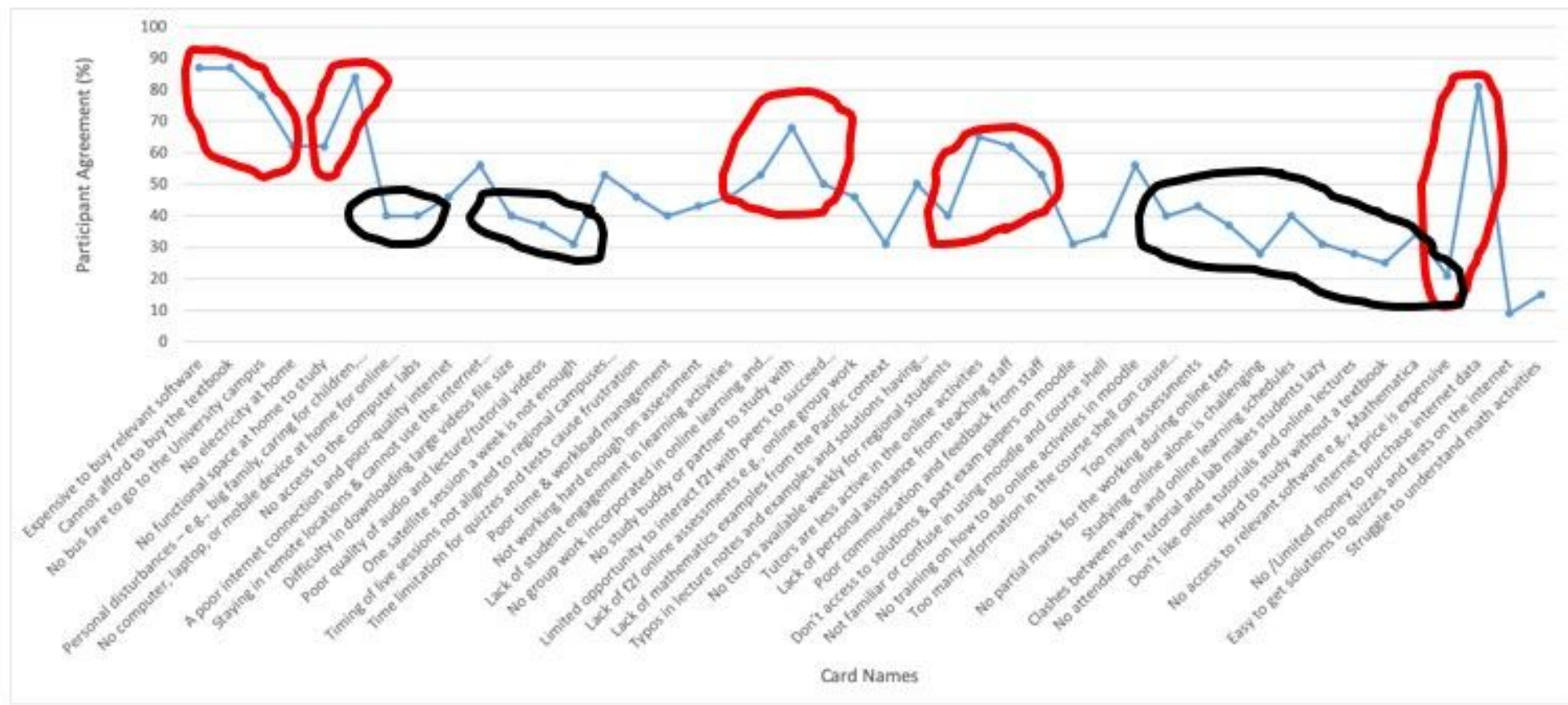

\section{Figure 3}

Shows the portion along the right edge of Figure 2 and indicates how many participants agree with each paired combination of cards.
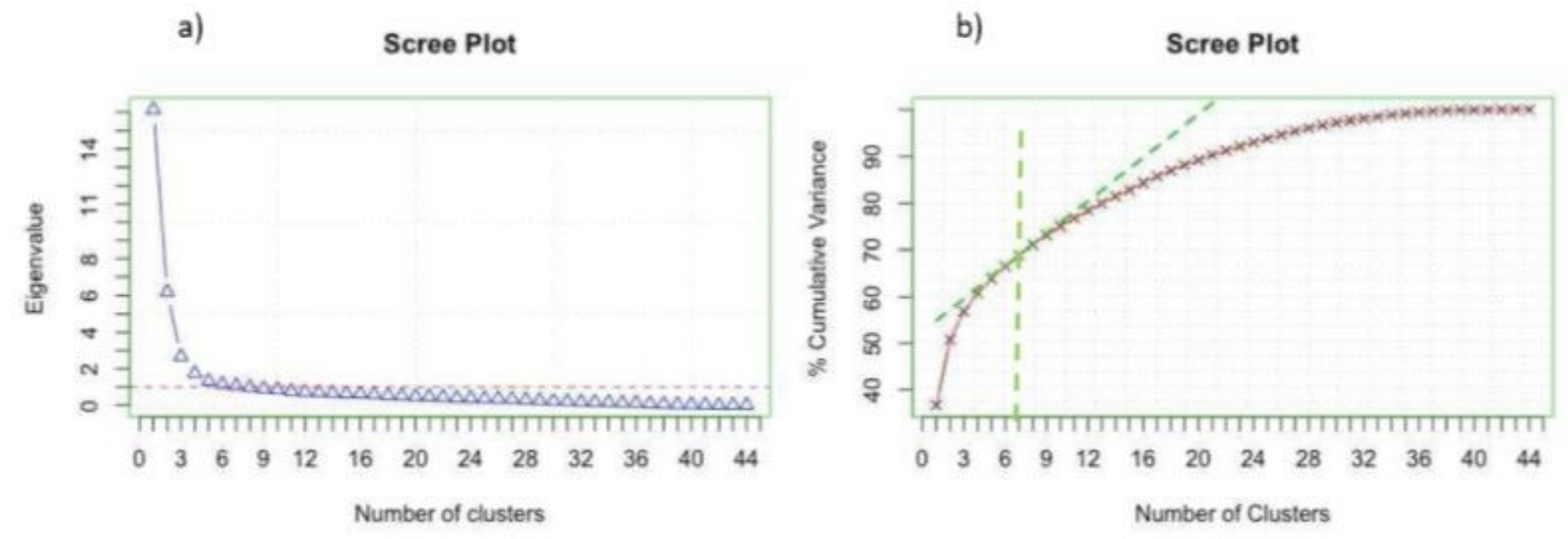

\section{Figure 4}

Determining the optimal number of categories. a) The scree plot for the initial variables. B) The scree plot analysis. 


\section{MDS Scree Plot}

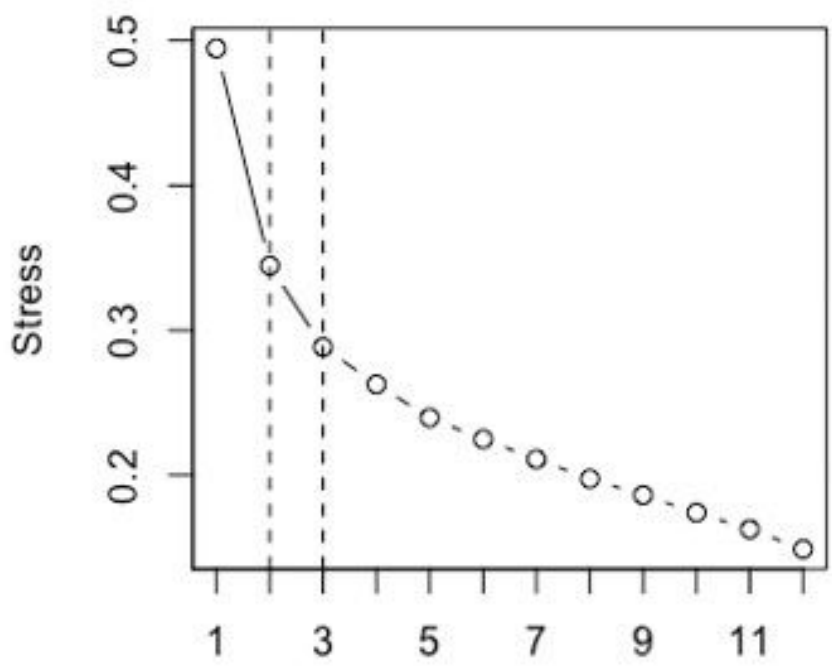

(a) Number of Dimensions

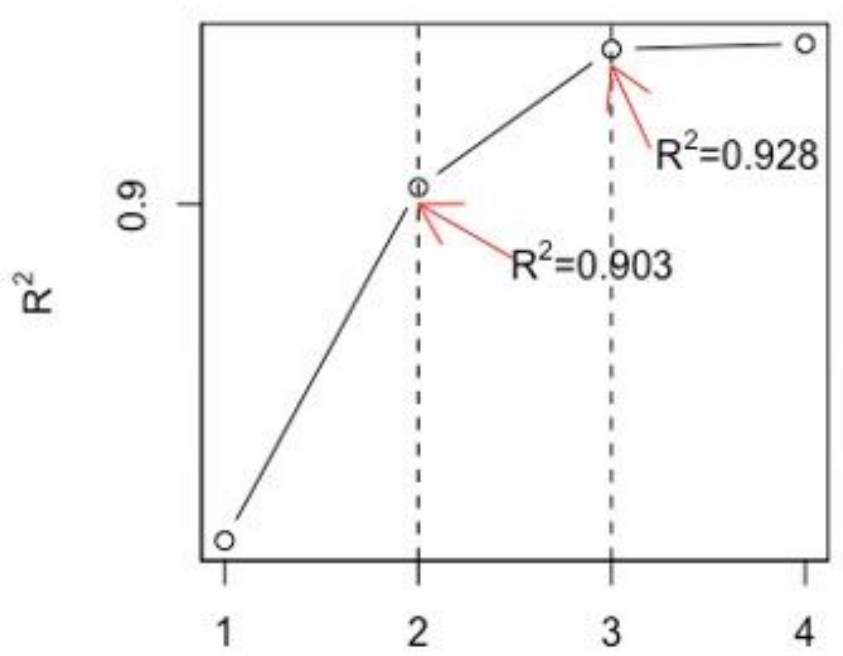

(b)

Number of Dimensions

\section{Figure 5}

The graph of stress against the number of dimensions (a) and R2 versus the number of dimensions (b)

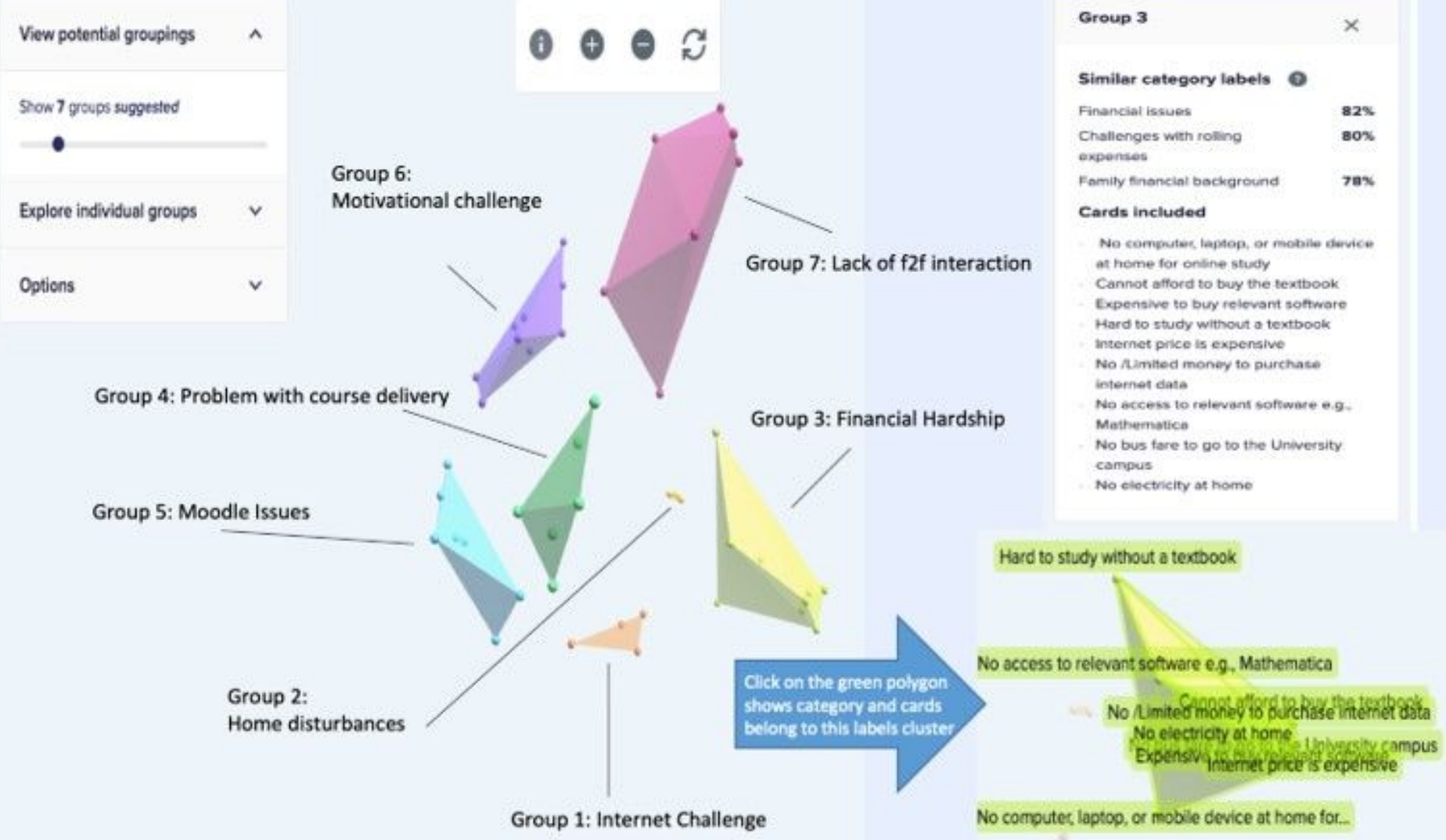


Figure 6

The 3DCV of the clustering results in Table 1. Using 3DCV produced seven-cluster solutions with each cluster shown in different colours. These polygon groups can be interpreted as possible categories for IA.

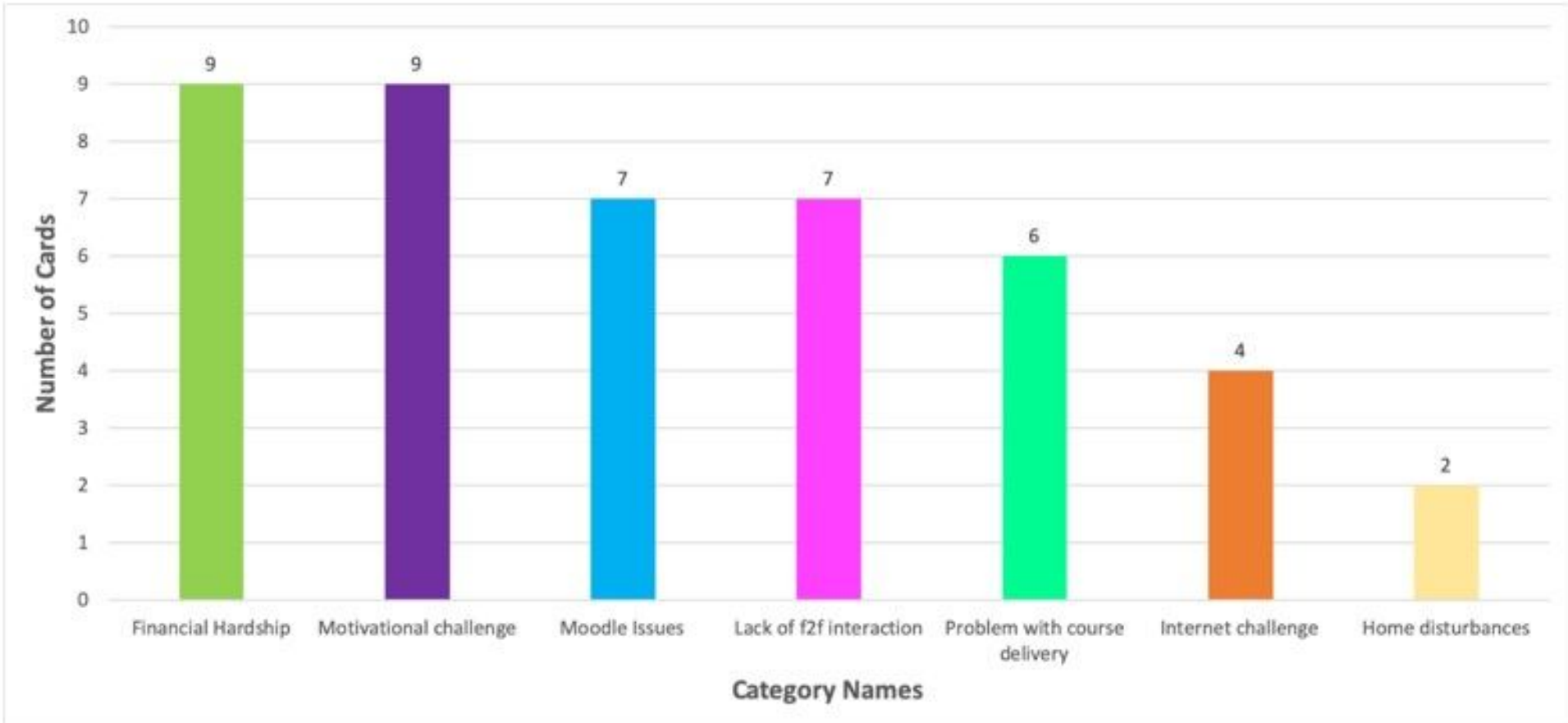

Figure 7

For clear visualisation, Bar graph of Figure 2 with the number of cards in each polygon. 


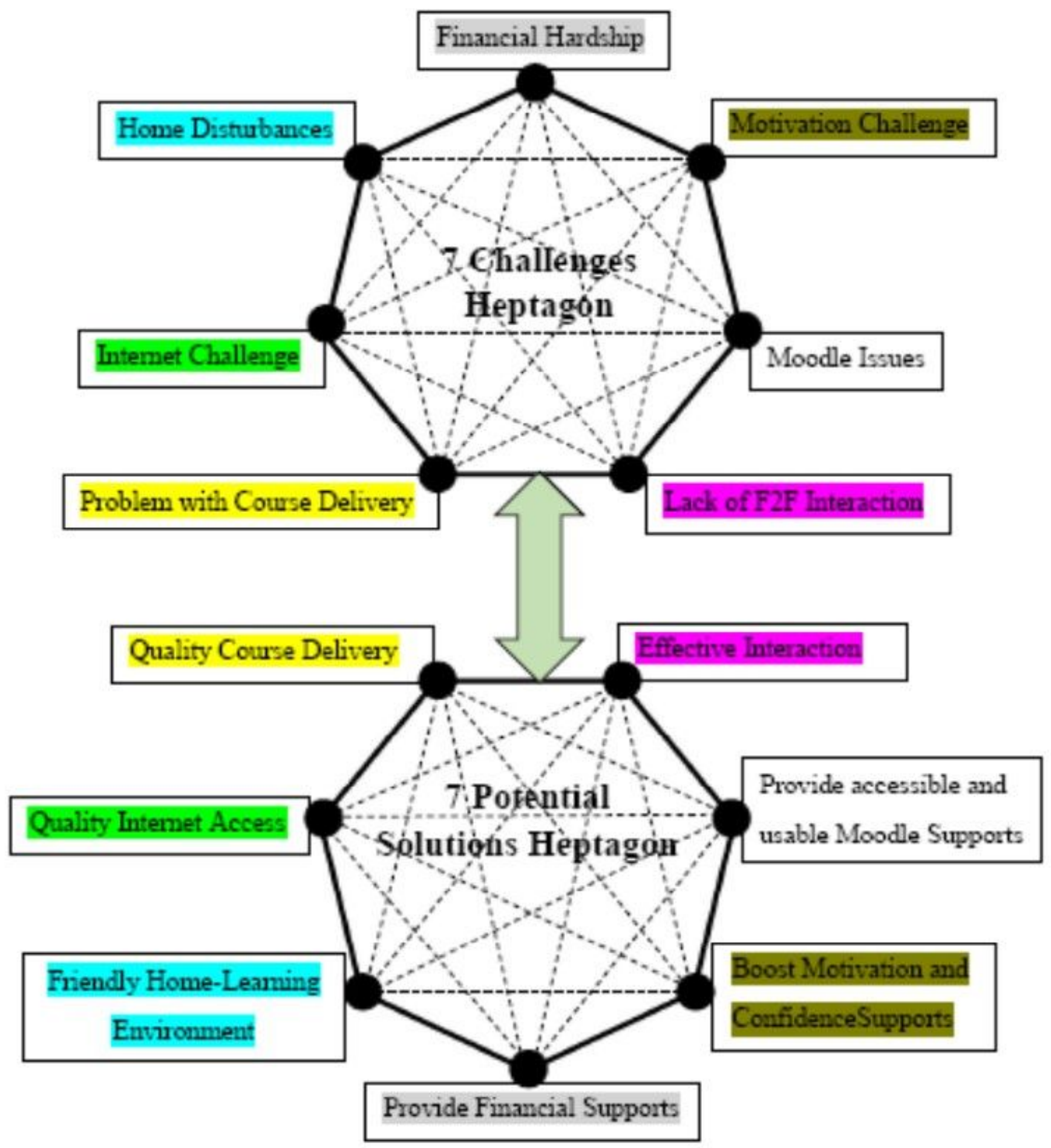

Figure 8

Potential solutions for participants' challenges 